\title{
Consumer acceptance of dairy products with a saturated fatty acid-reduced, monounsaturated fatty acid-enriched content
}

\author{
Oonagh Markey, ${ }^{*} \dagger^{1,2}$ Kallis Souroullas, ${ }^{*}$ Colette C. Fagan, ${ }^{*}$ Kirsty E. Kliem, $\ddagger$ Dafni Vasilopoulou, ${ }^{*} \dagger$

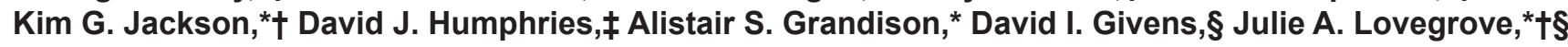 \\ and Lisa Methven* \\ ${ }^{*}$ Department of Food and Nutritional Sciences, and \\ †Hugh Sinclair Unit of Human Nutrition and Institute for Cardiovascular and Metabolic Research (ICMR), University of Reading, Reading, \\ RG6 6AP, United Kingdom \\ $\ddagger$ Animal, Dairy and Food Chain Sciences, University of Reading, Reading, RG6 6AP, United Kingdom \\ §Institute for Food, Nutrition and Health, University of Reading, Reading, RG6 6AR, United Kingdom
}

\begin{abstract}
Agriculture-based reformulation initiatives, including oleic acid-rich lipid supplementation of the dairy cow diet, provide a novel means for reducing intake of saturated fatty acids (SFA) at a population level. In a blinded manner, this study evaluated the consumer acceptance of SFA-reduced, monounsaturated fatty acid-enriched (modified) milk, Cheddar cheese, and butter when compared with control and commercially available comparative samples. The effect of providing nutritional information about the modified cheese was also evaluated. Consumers $(\mathrm{n}=115)$ rated samples for overall liking (appearance, flavor, and texture) using 9 -point hedonic scales. Although no significant differences were found between the milk samples, the modified cheese was liked significantly less than a regular-fat commercial alternative for overall liking and liking of specific modalities and had a lower liking of texture score compared with the control cheese. The provision of health information significantly increased the overall liking of the modified cheese compared with tasting the same sample in a blinded manner. Significant differences were evident between the butter samples for overall liking and modalities of liking; all of the samples were significantly more liked than the commercial butter and sunflower oil spread. In conclusion, this study illustrated that consumer acceptance of SFA-reduced, monounsaturated fatty acid-enriched dairy products was dependent on product type. Future research should consider how optimization of the textural properties
\end{abstract}

\footnotetext{
Received September 27, 2016.

Accepted June 16, 2017.

${ }^{1}$ Corresponding author: o.markey@lboro.ac.uk

${ }^{2}$ Present address: School of Sport, Exercise and Health Sciences, Loughborough University, Loughborough, LE11 3TU, United Kingdom.
}

of fatty acid-modified (and fat-reduced) cheese might enhance consumer acceptance of this product.

Key words: cardiovascular disease, consumer acceptance, dairy product, monounsaturated fatty acid, saturated fatty acid

\section{INTRODUCTION}

It is well established that supplementation of the dairy cow diet with plant oil, oilseeds, or marine lipids can be used as a strategy to partially replace the SFA content of ruminant milk with MUFA and, to a more limited extent, PUFA (Baer et al., 2001; Givens, 2008; Lourenço et al., 2010; Lock et al., 2014; Kliem and Shingfield, 2016). Findings from a systematic review suggest that consumption of modified dairy products, in which SFA was partially replaced with MUFA or PUFA, had a beneficial effect on plasma lipid markers of cardiovascular disease risk (Livingstone et al., 2012). Replacement of regular dairy products with SFA-reduced alternatives is one approach that could facilitate achievement of the SFA dietary recommendations for human health (i.e., to $\leq 10 \%$ of total energy; COMA, 1994) while minimizing the necessity for consumers to make significant changes to their habitual diet (Givens and Shingfield, 2006; Markey et al., 2014, 2017). Consequently, this reformulation initiative has the potential to provide a sustainable means of reducing the entry of SFA into dairy products and the wider food chain.

Sensory characteristics are one of the most influential determinants of food preference (Moskowitz et al., 2008). Thus, it is necessary to consider the potential impact of milk fatty acid (FA) modification on the sensorial characteristics (including texture and flavor) of milk and milk-derived foods, which are likely to relate to consumer acceptance and are key drivers in the commercial success of foods (Chilliard and Ferlay, 2004; Moskowitz et al., 2008). It is expected that reducing the SFA content will lead to a reduction in the melting point 
of the dairy products and thus affect properties including texture, spreadability, and mouthfeel (Rios et al., 2014). Some studies have highlighted that FA composition may alter the textural profile of cheese (Palmquist et al., 1993; Chilliard and Ferlay, 2004; Jones et al., 2005; Givens and Shingfield, 2006). Conversely, other studies have shown no effect of PUFA supplementation of the ruminant diet, which predominantly incorporated fish oil, on the sensory characteristics of milk (Baer et al., 2001; Ramaswamy et al., 2001; Kitessa et al., 2004; Lynch et al., 2005), cheese (Jones et al., 2005; VargasBello-Pérez et al., 2015), or butter (Baer et al., 2001). More research is needed to examine the acceptability of milk and dairy products produced from ruminants that have been subjected to a period of oleic acid-rich supplementation. Although the aforementioned studies have evaluated the sensory properties of FA-modified milk or dairy products in trained panelists or consumers, further research is needed to provide a combined overview of the consumer acceptance and sensory profile of dairy products that have been produced from SFA-reduced, MUFA-enriched milk.

As well as gaining insight into the general liking tendencies of a population, it is important to identify groups of consumers that are homogeneous with regard to their overall liking of products using cluster analysis (Beck et al., 2015). A previous cluster analysis of liquid dairy products highlighted that liking varied according to age, sex, and income (Richardson-Harman et al., 2000). Using a cluster approach, we have shown that a distinct cluster of consumers that were representative of the UK population with regard to age, sex, body mass index (BMI), and socioeconomic class (SEC) had less of a preference for a range of reformulated, sugarreduced products when compared with regular-sugar alternatives (Markey et al., 2015). To our knowledge, no study has used a cluster approach to investigate consumer acceptance of FA-modified dairy products and to examine whether consumer clusters of liking for such products are associated with sociodemographic characteristics.

Furthermore, the effect of nutrition information on product liking and purchase intent needs to be considered (Kähkönen et al., 1996). It has been previously illustrated that acceptance may be dependent on the product type as well as information provided to consumers about fat content of a specific product (Kähkönen et al., 1996; Westcombe and Wardle, 1997; Rapp et al., 2009). The objective of the current study was to examine, in a blinded manner, the study population's general acceptance and purchase intent of SFA-reduced, MUFA-enriched (modified) milk, Cheddar cheese, and butter (control) and commercially available comparators.

\section{MATERIALS AND METHODS}

\section{Bovine Supplementation Regimen}

A bovine supplementation regimen was used to supply raw milk for production of modified dairy products. The production period took place from November 2014 to May 2015 and has been described previously (K. E. Kliem, D. J. Humphries, O. Markey, D. Vasilopoulou, C. C. Fagan, A. S. Grandison, S. Todd, D. I. Givens, and J. A. Lovegrove, unpublished data). Briefly, the habitual TMR diet of 41 multiparous Holstein-Friesian dairy cows $[205 \mathrm{~d}$ in lactation $(\mathrm{SE}=7.2)$; milk yield at start $=33.4 \mathrm{~L} / \mathrm{d}(\mathrm{SE}=0.91)]$ was supplemented with approximately $1 \mathrm{~kg} / \mathrm{cow}$ per day of high-oleic sunflower oil $[80 \mathrm{~g} / 100 \mathrm{~g}$ of total FA in the form of oleic acid (C18:1 cis-9); AAK Ltd., Hull, UK] for a $\geq 28$-d period at the Centre for Dairy Research (University of Reading, Reading, Berkshire, UK).

\section{Manufacturing Process of the Modified and Control Dairy Products}

The SFA-reduced, MUFA-enriched (modified) milk, Cheddar cheese, and butter were produced from raw milk collected after cows had been supplemented with high-oleic sunflower oil for $\geq 4$ wk. Control raw milk, Cheddar cheese, and butter with FA profiles that were representative of commercial retail dairy products were supplied by Arla UK Plc. (Taw Valley Creamery, North Tawton, UK). The details for milk production and butter and cheese making were previously given (K. E. Kliem, D. J. Humphries, O. Markey, D. Vasilopoulou, C. C. Fagan, A. S. Grandison, S. Todd, D. I. Givens, and J. A. Lovegrove, unpublished data) and are described briefly below.

All UHT modified and control milks were processed in single batches $(1,400 \mathrm{~kg}$ ) at Framptons Ltd. (Shepton Mallet, Somerset, UK). Prior to UHT processing, control milk was standardized to match the fat content of the modified milk $(2.8 \mathrm{~g} / 100 \mathrm{~g})$. Both raw modified milk and standardized control milk were preheated to $85^{\circ} \mathrm{C}$ using a plate heat exchanger and homogenized. Direct steam infusion was used to heat the milk to $142^{\circ} \mathrm{C}$ for $5 \mathrm{~s}$ (Framptons Ltd., Shepton Mallet, Somerset, UK). Subsequently, the milk was cooled to $5^{\circ} \mathrm{C}$ and aseptically packaged into $330-\mathrm{mL}$ cartons and stored at $4^{\circ} \mathrm{C}$.

Modified Cheddar cheese was manufactured at the University of Reading's Food Processing Centre (Reading, Berkshire, UK) as a single batch $(180 \mathrm{~kg})$. Processing parameters were selected to mimic, at pilot scale, the process used at Arla UK Plc. to produce the single batch of control Cheddar cheese $(180 \mathrm{~kg})$. After pro- 
duction, the cheese was vacuum packed and placed in an $8^{\circ} \mathrm{C}$ ripening room for 3 mo. After ripening, cheese was apportioned into $350 \mathrm{~g}$, vacuum packed, and stored at $2^{\circ} \mathrm{C}$.

Modified butter was manufactured as a single batch $(80 \mathrm{~kg})$ at Ty Tanglwyst Dairy (Bridgend, South Wales, UK). A single batch of control butter $(80 \mathrm{~kg})$ was provided by Arla UK Plc. Butter was apportioned into 250 $\mathrm{g}$, packaged in butter wrap, and frozen until required.

\section{Dairy Product Samples}

Four UHT milk, mild Cheddar cheese, and butter and spread samples were evaluated in this study. The nutritional profile and manufacturer details of the dairy product samples are given in Table 1. Nutritional analysis (energy and macronutrient content) of the modified and control samples was conducted in duplicate by SGS United Kingdom Ltd. (ISO 17025 accredited laboratory; London, UK). Fat content was determined by low-resolution proton nuclear magnetic resonance. Protein content was calculated by multiplying the total nitrogen, determined by the Dumas method, by a standard nitrogen conversion factor of 6.25 to account for the fraction of NPN in each sample (Sriperm et al., 2011). Carbohydrate content was calculated by difference using the Atwater general system (Merrill and Watt, 1973). Sodium content analysis was carried out by duplicate by inductively coupled plasma-optical emission spectrometry at Quaternary Scientific (QUEST, School of Archaeology, Geography and Environmental Science, Reading, Berkshire, UK). Lipid extracted from all 12 milk, cheese, and butter samples was analyzed in triplicate for FA composition by GC-flame ionization detection using a standardized procedure (Table 1; Supplemental Table S1, https://doi.org/10.3168/jds .2016-12057; Kliem et al., 2013).

\section{Sample Preparation for Sensory Analyses}

The milk, cheese, and butter samples were prepared up to $3 \mathrm{~h}$ in advance but kept under a refrigeration temperature of $4^{\circ} \mathrm{C}$. Prior to serving, all samples were given $40 \mathrm{~min}$ to equilibrate to room temperature (21 $\left.\pm 1^{\circ} \mathrm{C}\right)$. Samples of cheese $(10 \mathrm{~g})$ were presented on clear plastic Petri dishes. Butter and spread samples $(1.5 \mathrm{~g})$ were spread onto $4 \mathrm{~cm} \times 4 \mathrm{~cm}$ pieces of white pita bread (Sainsbury's, London, UK) as previously described (Krause et al., 2007). Milk samples (30 mL) were presented in clear crystal polystyrene cups. All product types were presented in an unbranded manner and were labeled with 3-digit randomized codes. Carryover effects were minimized by providing prompts on when to cleanse palates with readily available low-salt crackers (Carr's Table Water Crackers; United Biscuits Ltd., Hayes, UK) and water and presenting samples in a monadic sequential manner.

\section{Sensory Analyses and Consumer Tests}

All sensory analysis by trained panel and consumer tests were carried out at the Sensory Science Centre (University of Reading) in ventilated, isolated, climate controlled $\left(22 \pm 1^{\circ} \mathrm{C}\right)$ sensory booths under artificial daylight. All questionnaire design and data collection were carried out using Compusense Software (Compusense Cloud, Guelph, Ontario, Canada).

\section{Quantitative Descriptive Analysis}

A trained 10-member sensory panel consisting of 10 assessors ( 9 women, 1 man; aged 35-60 yr) with $\geq 2$ yr experience developed a consensus vocabulary on each dairy product type using quantitative descriptive analysis (QDA). Vocabularies were developed for appearance, odor, taste, flavor, texture and mouthfeel, and aftertaste or aftereffect attributes of the dairy products in reference to published literature (Drake et al., 2001; Krause et al., 2007; Oupadissakoon et al., 2009; Tables $2,3$, and 4$)$. Although the butter was presented on pita bread (to relate results to the consumer liking data), the panel was asked to manipulate the product in their mouths and focus only on the attributes of the butter. After the terminology development phase, rating was carried out in isolated booths where, within each product type, samples were presented in a balanced order to assessors in a monadic sequential manner. Warm water was used as a palate cleanser between samples (40 \pm $5^{\circ} \mathrm{C}$ ). Attributes were evaluated using $100-\mathrm{mm}$ unstructured line scales (anchors of 0 and 100 developed per attribute; Table 2). The different product types were evaluated on different days. Each product set contained 4 samples, and in all sets assessors rated samples over a 30-min period, in duplicate, on 2 separate days. The enforced rest time between samples within each set was $1 \mathrm{~min}$. In each session the modalities were rated in the following order: appearance, odor, mouthfeel, taste, flavor, and finally, following a 30-s delay, aftereffects.

\section{Consumer Screening and Recruitment}

Untrained, apparently healthy consumers aged 25 to $70 \mathrm{yr}$ were recruited to the study. The study was given a favorable opinion for conduct by the University of Reading's School of Chemistry, Food and Pharmacy Research Ethics Committee (study number 15/14), and all consumers provided written informed consent before study entry. 
Consumers represented 6 predetermined demographic categories based on sex (men and women), age (young $=25-47 \mathrm{yr}$; old $=48-70 \mathrm{yr}$ ), and SEC (upper $=$ $1-4$; lower $=5-8$ ). The SEC was determined according to the 2010 National Statistics Socio-Economic Classification Guidelines (Rose and Pevalin, 2010). Based on previous work (Markey et al., 2015), a sample size of 100 consumers was deemed necessary to detect a difference in overall liking (primary outcome measure) of 2 on a 9-point hedonic scale between products at $80 \%$ power and $P<0.05$. With the allowance for a $20 \%$ dropout rate, 115 consumers were recruited to the study. Participants were reimbursed for their time and travel with a small payment.

\section{Consumer Acceptability Test}

Consumers attended 1 session (approximately $50 \mathrm{~min}$ ) and were masked to the true purpose of the study; they were told that the study would be testing the acceptance and purchase intent for different dairy products. Consumer BMI [weight $(\mathrm{kg})$ divided by height squared $\left(\mathrm{m}^{2}\right)$ ] was calculated from weight and height (measured to the nearest $0.1 \mathrm{~kg}$ and $0.1 \mathrm{~cm}$, respectively).

\section{Acceptability of Dairy Products that Were Presented in a Blinded Manner}

Three sets of dairy products were served to consumers in the following order: (1) cheese, (2) milk, and (3) butter and spread. Samples were presented to consumers in this order to ensure that the time between tasting the strongest 2 samples sets (i.e., cheese and butter) was maximized. The 4 samples in each product set were presented to consumers in a balanced order. Consumers evaluated overall liking and liking of specific modalities - namely appearance, flavor, and texture or mouthfeel - on 9-point hedonic category scales $(1=$ dislike

Table 1. Nutritional content of the cheese, milk, and butter and spread samples evaluated in the study

\begin{tabular}{|c|c|c|c|c|c|c|c|c|c|c|}
\hline Item $^{1}$ & $\begin{array}{l}\text { Energy, } \\
\text { kcal/100 g }\end{array}$ & $\begin{array}{l}\text { Protein, } \\
\text { g/100 g }\end{array}$ & $\begin{array}{c}\text { Carbohydrate, } \\
\text { g/100 g }\end{array}$ & $\begin{array}{l}\text { Fat, } \\
\mathrm{g} / 100 \mathrm{~g}\end{array}$ & $\begin{array}{l}\mathrm{SFA}^{2} \\
\mathrm{~g} / 100 \mathrm{~g}\end{array}$ & $\begin{array}{l}\text { PUFA, }{ }^{2} \\
\mathrm{~g} / 100 \mathrm{~g}\end{array}$ & $\begin{array}{l}\text { MUFA, }^{2} \\
\mathrm{~g} / 100 \mathrm{~g}\end{array}$ & $\begin{array}{l}\text { trans- } \\
\text { MUFA, } \\
\mathrm{g} / 100 \mathrm{~g}\end{array}$ & $\begin{array}{l}\text { Sodium, } \\
\mathrm{g} / 100 \mathrm{~g}\end{array}$ & $\begin{array}{l}\text { Salt, } \\
\text { g/100 g }\end{array}$ \\
\hline \multicolumn{11}{|l|}{ Milk } \\
\hline Control $^{3,4}$ & 50 & 2.9 & 4.4 & 2.3 & 1.6 & 0.1 & 0.5 & 0.1 & 0.0 & 0.0 \\
\hline Comp1 $1^{5,6}$ & 129 & 3.4 & 4.6 & 3.6 & 2.3 & 0.1 & 0.9 & 0.1 & 0.0 & 0.0 \\
\hline Comp2 $2^{5,6}$ & 47 & 3.5 & 4.6 & 1.6 & 1.0 & 0.1 & 0.4 & 0.1 & 0.0 & 0.0 \\
\hline Control $^{3,4}$ & 405 & 22.8 & 3.5 & 33.3 & 22.3 & 1.0 & 7.8 & 0.9 & 0.7 & 1.8 \\
\hline Comp1 $1^{5,6}$ & 416 & 25.4 & 0.1 & 34.9 & 23.2 & 1.0 & 8.4 & 0.9 & 0.7 & 1.8 \\
\hline Comp2 $2^{5,6}$ & 302 & 26.0 & 0.1 & 22.0 & 13.5 & 0.7 & 6.3 & 0.9 & 0.7 & 1.8 \\
\hline \multicolumn{11}{|c|}{ Butter and spread } \\
\hline Modified $^{3,4}$ & 729 & 0.4 & 1.4 & 80.2 & 38.8 & 3.0 & 33.0 & 7.7 & 0.6 & 1.5 \\
\hline Control $^{3,4}$ & 739 & 0.2 & 2.2 & 81.1 & 51.8 & 3.2 & 20.7 & 2.7 & 0.7 & 1.8 \\
\hline Comp $1^{5}$ & 730 & 0.7 & 0.7 & 80.5 & 46.3 & 3.5 & 25.8 & 4.4 & 0.7 & 1.8 \\
\hline
\end{tabular}

${ }^{1}$ Modified and control dairy products were produced for use in cohort 2 of the REplacement of SaturatEd fat in dairy on Total cholesterol (RESET) study human intervention trial, which will determine the effect of consuming fatty acid-modified dairy products, where SFA have been partially replaced with cis-MUFA, on a range of cardiometabolic risk markers compared with regular (control) dairy products (ClinicalTrials.gov NCT02089035; Markey et al., 2017). The modified dairy product production period took place from November 2014 to May 2015 and has been described previously (K. E. Kliem, D. J. Humphries, O. Markey, D. Vasilopoulou, C. C. Fagan, A. S. Grandison, S. Todd, D. I. Givens, and J. A. Lovegrove, unpublished data). Modified = UHT SFA-reduced, MUFA-enriched milk (Framptons Ltd., Somerset, UK); fat- and SFA-reduced, MUFA-enriched mild Cheddar cheese (Food Processing Centre, Reading, UK); and SFA-reduced, MUFA-enriched butter (Ty Tanglwyst Dairy, Bridgend, South Wales, UK). Control = UHT regular-SFA milk (Framptons Ltd.); regular-fat mild Cheddar cheese (Arla Foods, Devon, UK); and regular-fat butter (Arla Foods). Along with the modified and control samples from the RESET study, 2 commercially available branded comparators of each product (Comp1 and 2) were selected based on their fat composition (all products) and level of maturation (cheese only). Comp1 (commercial comparator 1) = UHT whole milk (Sainsbury's Whole Long Life Milk, Sainsbury's Supermarkets Ltd., London, UK); regular-fat mild Cheddar cheese (Tesco Mild Cheddar, Welwyn Garden City, UK); regular-fat, SFA-reduced, MUFA-enriched butter produced by supplementation of the bovine diet with rapeseed oil (Softer Butter product, Marks and Spencer Plc., London, UK). Comp2 (commercial comparator 2) = UHT semiskimmed milk (Sainsbury's Semi-Skimmed Long Life Milk, Sainsbury's Supermarkets Ltd.); fat-reduced mild Cheddar cheese (Tesco Lighter Mild Cheddar); and regular-fat spreadable butter containing 31\% sunflower oil (Buttery and Spreadable, Yeo Valley Farms Production Ltd., Bristol, UK).

${ }^{2}$ The fatty acid profile of fat extracted from the products was calculated by GC-flame ionization detection (Kliem et al., 2013).

${ }^{3}$ Nutritional analysis (energy and macronutrient content) was conducted by SGS United Kingdom Ltd. (Cheshire, UK).

${ }^{4}$ Salt content was estimated by multiplying the sodium content by 2.5 .

${ }^{5}$ Nutritional profile was based on manufacturer labels.

${ }^{6}$ Sodium content was estimated by dividing the salt content by 2.5 . 
extremely; 9 = like extremely; Peryam and Pilgrim, 1957; Beckley et al., 2012). Rating of purchase intent was evaluated on 5 -point hedonic scales $(1=$ definitely would not buy or replace; $5=$ definitely would buy or replace; Beckley et al., 2012). The enforced rest time between samples within each set was $1 \mathrm{~min}$. To minimize the potential for carryover effects between dairy products, different sample sets were separated by completion of questionnaires on sociodemographic characteristics (taking approximately $2 \mathrm{~min}$ ).

\section{Acceptability of SFA-Reduced, MUFA-Enriched Cheese with Nutritional Information}

Modified cheese was presented to consumers in an unblinded manner with nutrition information (i.e., "Saturated fat-reduced Cheddar: This product has 15\% less total fat and 34\% less saturated fat than regular Cheddar cheese") for assessment of overall liking, purchase intent, and product replacement. Consumers evaluated overall liking of the SFA-reduced cheese (9-point hedonic category scale) and purchase intent (5-point hedonic scale), as described previously.

\section{Food Neophobia Scale}

The Pliner and Hobden 10-item Food Neophobia Scale (FNS; Pliner and Hobden, 1992) was used to assess willingness to try new foods. The FNS items were answered using a 7-point Likert rating scale (1 $=$ strongly disagree $; 7=$ strongly agree). Total FNS scores were calculated for each consumer after reversing negative statements (items 1, 4, 6, 9, and 10; Pliner and Hobden, 1992).

\section{Frequency of Dairy Product Consumption}

Following the tasting sessions, consumers were asked to quantify their typical consumption of milk, cheese, and butter using a 10-point category scale from $1=$ never to $10=6+$ times $/ \mathrm{d}$, with 4 representing once per week and 7 representing once per day. They also de-

Table 2. Descriptive characteristics of the milk samples that differed significantly $(P<0.05)$ as evaluated by a trained sensory panel $(\mathrm{n}=10)^{1,2}$

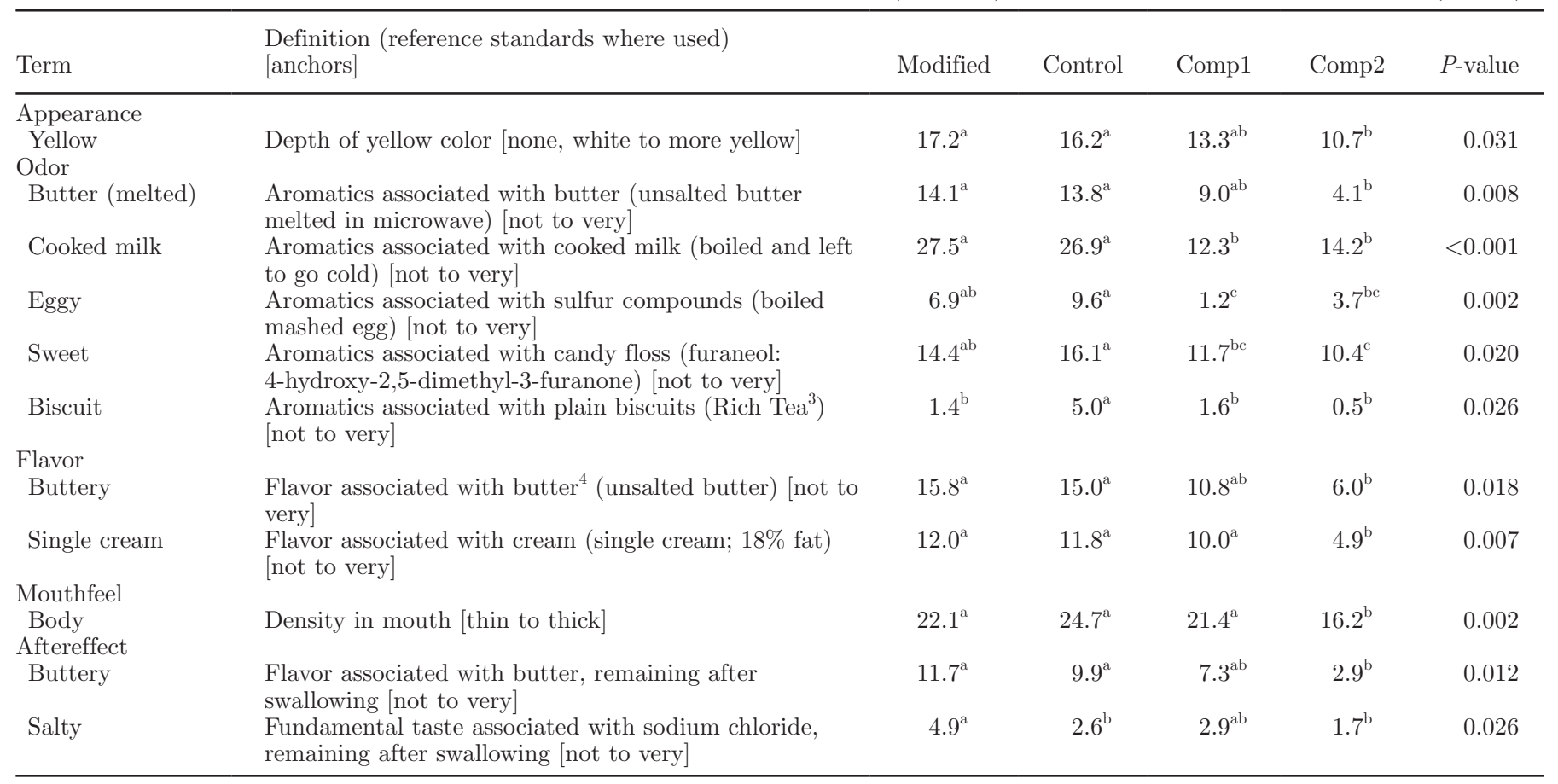

${ }^{\mathrm{a}-c}$ Values within a row with different superscripts are significantly different $(P<0.05)$. Attributes that were not significantly different between the milk samples were as follows. Appearance: shiny, body. Odor: margarine, mild cheese, single cream, caramel, malty, cardboard, metallic. Taste: sweet, savory, sour, salty, metallic. Flavor: margarine, cooked milk, eggy, mild cheese, biscuit, caramel, malty, cardboard. Mouthfeel: drying, fatty, lingering, mouth cooling, powdery. Aftereffect: drying, margarine, metallic, mouth cooling.

${ }^{1}$ Data were analyzed by 2-way ANOVA with sample and assessors fitted as fixed and random effects, respectively. Tukey's post hoc tests were used to identify significant differences between milk samples.

${ }^{2}$ Modified = SFA-reduced, MUFA-enriched UHT milk; control = UHT regular-SFA milk; Comp1 = commercial comparator 1 (UHT whole milk); Comp2 = commercial comparator 2 (UHT semiskimmed milk).

${ }^{3}$ Rich Tea biscuits (McVities, Pladis, Hayes, UK).

${ }^{4}$ Unsalted butter (Anchor Unsalted Butter, Arla Foods, Devon, UK). 
clared the type of milk they usually consumed (whole, semiskimmed, skim, or other) and quantified their daily milk consumption (5-point scale; $1=$ less than 142 $\mathrm{mL} / \mathrm{d} ; 5=>568 \mathrm{~mL} / \mathrm{d})$.

\section{Statistical Analysis}

The QDA profiling data were analyzed in SENPAQ (version 5.01; QI Statistics, Reading, UK) by 2-way

Table 3. Descriptive characteristics of the cheese samples that differed significantly $(P<0.05)$ as evaluated by a trained sensory panel $(\mathrm{n}=$ $10)^{1,2}$

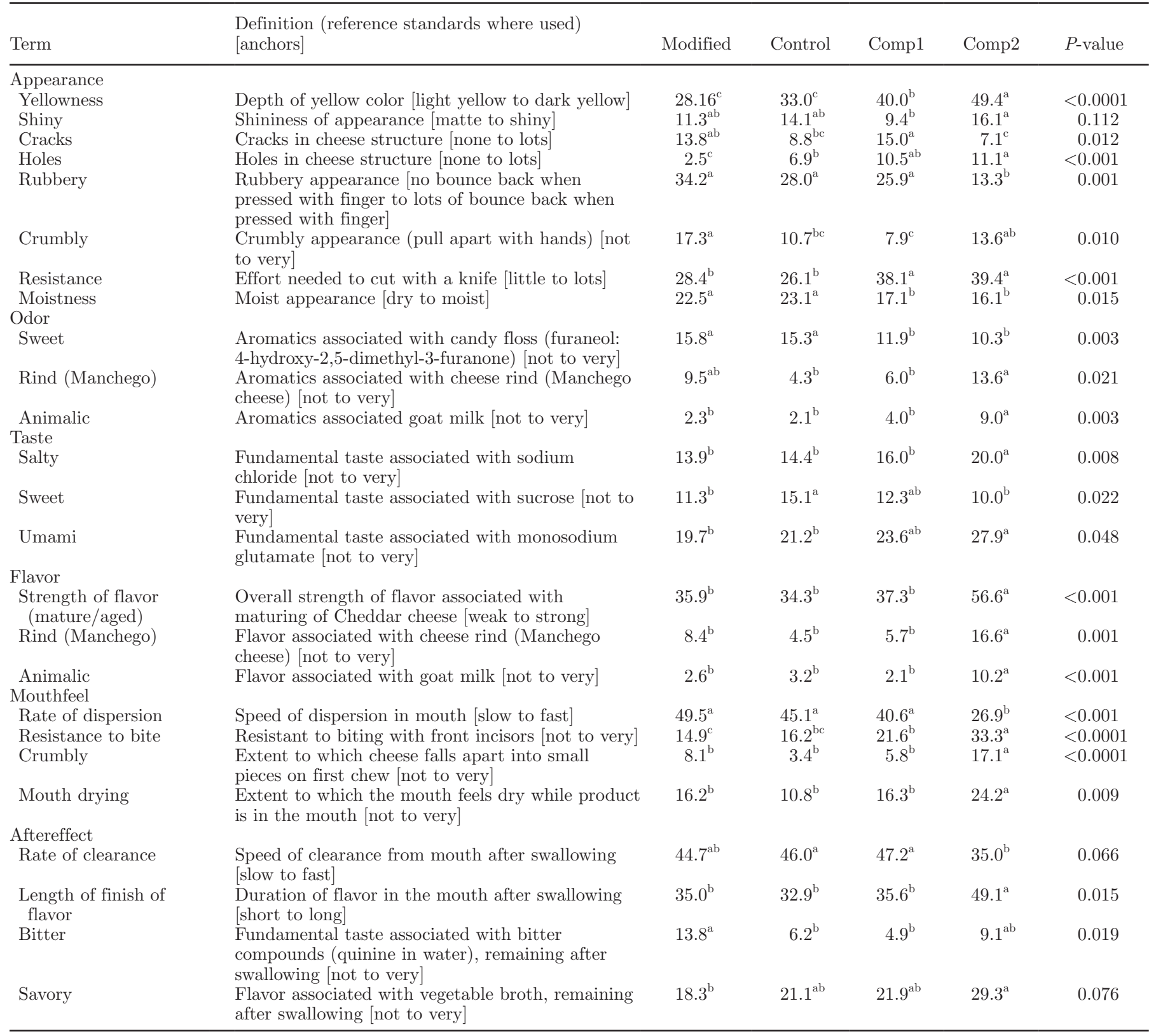

$\overline{{ }^{a-c} \text { Values within a row with different superscripts are significantly different }(P<0.05) \text {. Attributes that were not significantly different between }}$ the cheese samples were as follows. Appearance: flakiness (pull apart with hands). Odor: strength of odor, sour (lactic), savory, milky (pasteurized whole milk), melted butter, nutty (roasted hazelnuts), sweaty feet (butyric acid), sulfurous (brassica). Taste: sour. Flavor: sour/lactic, milky (pasteurized whole milk), melted butter, nutty (roasted hazelnuts), nutty (chestnuts), sulfurous (brassica). Mouthfeel: rubbery, mouth coating, salivating, tongue tingle, claggy. Aftereffect: tooth coating (sticky), salty, sour/lactic, metallic, mouth drying, salivating.

${ }^{1}$ Data were analyzed by 2-way ANOVA with sample and assessors fitted as fixed and random effects, respectively. Tukey's post hoc tests were used to identify significant differences between milk samples.

${ }^{2}$ Modified $=$ fat- and SFA-reduced, MUFA-enriched mild Cheddar cheese; control = regular-fat mild Cheddar cheese; Comp1 = commercial comparator 1 (regular-fat mild Cheddar cheese); Comp2 = commercial comparator 2 (fat-reduced mild Cheddar cheese). 
ANOVA, with sample and assessors fitted as fixed and random effects, respectively, and main effects tested against the interaction. Tukey's post hoc tests were used to identify significant differences between samples.

Consumer hedonic liking data were analyzed by analysis of covariance based on type III sum of squares (with product and consumers as fixed effects) when significant product $\times$ covariate $($ sex, age, or BMI) interactions were identified. Otherwise, data were analyzed by ANOVA. Tukey's post hoc tests for multiple comparisons were used to identify differences in the data. Agglomerative hierarchical cluster analysis (HCA) was performed on consumer overall liking data within each product category using Ward's method with Euclidean distances as the initial dissimilarities; automated truncation was used, which resulted in 3 consumer groups for each product type. Subsequently, ANOVA was used to identify differences in liking between consumer clusters. Statistical analyses of consumer data were performed using XLStat (version 2012; AddinSoft, Paris, France). Age, BMI, and FNS scores were dichotomized into low and high values given below and above the population median of $24.6 \mathrm{~kg} / \mathrm{m}^{2}, 44.0 \mathrm{yr}$, and 26 (minimum score $=10 ;$ maximum score $=70$; Pliner and Hobden, 1992), respectively. Paired-samples $t$-tests were used to compare overall liking and purchase intent between modified cheese samples presented with and without information. Data are presented as mean \pm standard deviation. Statistical significance was set at $P<0.05$.

\section{RESULTS}

\section{Sensory Characteristics of the Dairy Products}

The trained sensory panel used 42 attributes that were used to describe the milk samples; only 7 of these characteristics were significantly different between milks $(P<0.05$; Table 2$)$. When compared with comparators (Comp) 1 and 2 (see Table 1 for description), the modified control milk had significantly higher melted butter and cooked milk odor, buttery and single cream flavors, more body (mouthfeel), and a more buttery afteref-

Table 4. Descriptive characteristics of the butter and spread samples that differed significantly $(P<0.05)$ as evaluated by a trained sensory panel $(\mathrm{n}=10)^{1,2,3}$

\begin{tabular}{|c|c|c|c|c|c|c|}
\hline Term & $\begin{array}{l}\text { Definition (reference standards } \\
\text { where used) [anchors] }\end{array}$ & Modified & Control & Comp1 & Comp2 & $P$-value \\
\hline \multicolumn{7}{|l|}{ Appearance } \\
\hline Yellowness & $\begin{array}{l}\text { Depth of yellow color [light yellow to dark } \\
\text { yellow] }\end{array}$ & $36.3^{\mathrm{b}}$ & $50.6^{\mathrm{a}}$ & $51.8^{\mathrm{a}}$ & $42.3^{\mathrm{b}}$ & $<0.0001$ \\
\hline Shiny & Shininess of appearance [matte to shiny] & $37.8^{\mathrm{b}}$ & $28.4^{\mathrm{b}}$ & $60.1^{\mathrm{a}}$ & $67.1^{\mathrm{a}}$ & $<0.0001$ \\
\hline Water spots & Presence of water spots [none to lots] & $3.8^{\mathrm{a}}$ & $17.1^{\mathrm{a}}$ & $2.8^{\mathrm{a}}$ & $12.8^{\mathrm{a}}$ & 0.040 \\
\hline Body & $\begin{array}{l}\text { Density of appearance [thin consistency to } \\
\text { thick consistency] }\end{array}$ & $56.7^{\mathrm{a}}$ & $65.7^{\mathrm{a}}$ & $53.7^{\mathrm{a}}$ & $35.0^{\mathrm{b}}$ & $<0.0001$ \\
\hline \multicolumn{7}{|c|}{. } \\
\hline Fatty (vegetable not dairy) & $\begin{array}{l}\text { Aromatics associated with vegetable oil } \\
\text { (sunflower oil) [not to very] }\end{array}$ & $14.1^{\mathrm{b}}$ & $16.9^{\mathrm{ab}}$ & $22.2^{\mathrm{ab}}$ & $25.0^{\mathrm{a}}$ & 0.026 \\
\hline \multicolumn{7}{|c|}{ the } \\
\hline $\begin{array}{l}\text { How long butter and bread } \\
\text { stay separate in mouth }\end{array}$ & $\begin{array}{l}\text { Time taken for the butter and bread to } \\
\text { separate in mouth [short time to long time] }\end{array}$ & $44.3^{\mathrm{a}}$ & $52.6^{\mathrm{a}}$ & $42.6^{\mathrm{a}}$ & $18.1^{\mathrm{b}}$ & $<0.001$ \\
\hline Body & Density in mouth [thin to thick] & $50.3^{\mathrm{a}}$ & $52.5^{\mathrm{a}}$ & $39.4^{\mathrm{a}}$ & $15.3^{\mathrm{b}}$ & $<0.0001$ \\
\hline Rate of melting & Speed of melting in mouth [slow to fast] & $54.7^{\mathrm{bc}}$ & $49.4^{\mathrm{c}}$ & $65.2^{\mathrm{b}}$ & $83.6^{\mathrm{a}}$ & $<0.0001$ \\
\hline \multicolumn{7}{|c|}{ credint [110t we very] } \\
\hline Greasy lips & $\begin{array}{l}\text { Greasy film remaining on lips once product } \\
\text { swallowed [not to very] }\end{array}$ & $21.6^{\mathrm{a}}$ & $20.7^{\mathrm{a}}$ & $25.3^{\mathrm{a}}$ & $29.8^{\mathrm{a}}$ & 0.049 \\
\hline
\end{tabular}

\footnotetext{
${ }^{a-c}$ Values within a row with different superscripts are significantly different $(P<0.05)$. Attributes that were not significantly different between the butter samples were as follows. Odor: strength of odor, sour (lactic), creamy (dairy), sweet. Mouthfeel: cooling sensation, smooth, chalky, salivating, throat catch. Taste: sour, salty, sweet, metallic, bitter. Flavor: fatty (vegetable, not dairy). Aftereffect: sour, salty, fatty (vegetable, not dairy), creamy (dairy flavor), oily mouthfeel, bitter, throat catch.

${ }^{1}$ Data were analyzed by 2-way ANOVA, with sample and assessors fitted as fixed and random effects, respectively. Tukey's post hoc tests were used to identify significant differences between milk samples.

${ }^{2}$ Modified = regular-fat, SFA-reduced, MUFA-enriched butter; control = regular-fat butter; Comp1 = commercial comparator 1 (regular-fat, SFA-reduced butter); Comp2 = commercial comparator 2 (regular-fat spreadable butter).

${ }^{3}$ In each session the modalities were rated in the following order: appearance, odor, mouthfeel, taste, flavor, and, following a 30-s delay, aftereffects.
} 
fect (all $P<0.05$ ). A salty aftereffect was significantly higher in the modified milk compared with the other 3 samples $(P<0.05)$. For cheese, 53 attributes were identified (Table 3 ). The modified cheese had a significantly less yellow and holey appearance than all samples, had a more bitter aftereffect, and was less crumbly than control and Comp1 samples (all $P<0.05$ ). In comparison with the fat-reduced commercial cheese (Comp2), the modified cheese had a faster rate of dispersion in the mouth, more similar to the values for the regularfat samples (control and Comp1). Thirty-six butter attributes were identified (Table 4). The modified butter was significantly less yellow than Comp1 and 2, and the modified and control samples were less shiny than Comp1 and $2(P<0.05)$. In comparison with the commercial products, the modified and control samples were both significantly higher in body (appearance and mouthfeel) and had a less watery mouthfeel than the commercial blend of butter and sunflower oil (Comp2; all $P<0.05)$. The modified and control samples had a significantly less oily mouthfeel than Comp2 $(P<$ $0.05)$.

\section{Consumer Demographics}

In total, 115 consumers participated in the study. The study population was split relatively equally for sex (54 men, 61 women), age $(44.3 \pm 14.6 \mathrm{yr} ; \leq 44.0 \mathrm{yr}$ : $50 \%)$, FNS (26.3 $\pm 9.4 ; \leq 26.0: 52 \%)$, and SEC (1-4:
51\%; Rose and Pevalin, 2010). Mean BMI of consumers was $25.1 \pm 4.3 \mathrm{~kg} / \mathrm{m}^{2}$.

Our cohort was moderately health conscious, with $56 \%$ of consumers reporting that they often actively read the nutritional information on food labels when purchasing a product for the first time. When asked about their habitual intake of dairy products, 73.9, 94.8 , and $60.9 \%$ of consumers reported consuming cheese, milk, and butter (excluding margarine, vegetable oil spreads, and so on) $\geq 2$ to 4 times per week, respectively.

\section{Consumer Acceptance of SFA-Reduced, MUFA-Enriched Dairy Products}

Milk Samples. There was no significant difference in overall liking, liking of specific modalities, or purchase intent between the UHT milk samples (all $P>$ 0.05; Tables 5 and 6).

Cheese Samples. There was a significant difference in overall liking, liking of specific modalities, and purchase intent between the 4 cheese samples (all $P<0.05$; Tables 5 and 6 ). The modified cheese was significantly less liked than the commercial regular-fat Cheddar (Comp1; $P=0.007)$ and scored significantly lower in liking of specific modalities, including appearance $(P=$ $0.016)$, flavor $(P=0.013)$, texture liking $(P=0.001)$, and purchase intent $(P=0.007)$. The modified cheese was significantly lower than the control cheese in terms

Table 5. Mean overall liking scores ${ }^{1}$ for all consumers and consumer clusters ${ }^{2}$ for milk, cheese, and butter samples and across all product types ${ }^{3,4}$

\begin{tabular}{|c|c|c|c|c|c|c|c|c|c|}
\hline Product & Mean & SD & Mean & SD & Mean & SD & Mean & SD & $P$-value \\
\hline \multicolumn{10}{|l|}{ Milk } \\
\hline Overall group $(\mathrm{n}=115)$ & $6.1^{\mathrm{a}}$ & 1.9 & $6.3^{\mathrm{a}}$ & 1.7 & $6.1^{\mathrm{a}}$ & 2.0 & $6.4^{\mathrm{a}}$ & 1.6 & 0.313 \\
\hline Cluster $1(\mathrm{n}=30,26 \%)$ & $5.8^{\mathrm{b}}$ & 1.7 & $7.3^{\mathrm{a}}$ & 0.9 & $4.3^{\mathrm{c}}$ & 1.2 & $5.8^{\mathrm{b}}$ & 1.5 & $<0.0001$ \\
\hline Cluster $2(\mathrm{n}=65,57 \%)$ & $6.9^{\mathrm{ab}}$ & 1.5 & $6.6^{\mathrm{b}}$ & 1.4 & $7.4^{\mathrm{a}}$ & 1.4 & $7.2^{\mathrm{ab}}$ & 1.3 & 0.005 \\
\hline Cluster $3(\mathrm{n}=20,17 \%)$ & $4.1^{\mathrm{a}}$ & 1.4 & $3.8^{\mathrm{a}}$ & 1.2 & $4.5^{\mathrm{a}}$ & 1.9 & $4.6^{\mathrm{a}}$ & 1.1 & 0.351 \\
\hline \multicolumn{10}{|l|}{ Cheese } \\
\hline Cluster $1(\mathrm{n}=76,66 \%)$ & $7.0^{\mathrm{b}}$ & 1.1 & $7.0^{\mathrm{b}}$ & 1.2 & $7.5^{\mathrm{a}}$ & 0.8 & $7.1^{\mathrm{ab}}$ & 1.2 & 0.006 \\
\hline Cluster $2(\mathrm{n}=22,19 \%)$ & $4.4^{\mathrm{b}}$ & 1.4 & $6.2^{\mathrm{a}}$ & 1.7 & $6.1^{\mathrm{a}}$ & 1.2 & $3.6^{\mathrm{b}}$ & 1.4 & $<0.0001$ \\
\hline Cluster $3(\mathrm{n}=17,15 \%)$ & $4.8^{\mathrm{b}}$ & 1.9 & $5.0^{\mathrm{b}}$ & 1.9 & $4.3^{\mathrm{b}}$ & 1.7 & $7.4^{\mathrm{a}}$ & 0.8 & $<0.0001$ \\
\hline \multicolumn{10}{|l|}{ Butter and spread } \\
\hline Overall group $(\mathrm{n}=115)$ & $6.5^{\mathrm{b}}$ & 1.6 & $6.3^{\mathrm{b}}$ & 1.7 & $6.7^{\mathrm{b}}$ & 1.5 & $5.0^{\mathrm{a}}$ & 2.2 & $<0.0001$ \\
\hline Cluster $1(\mathrm{n}=39,34 \%)$ & $6.5^{\mathrm{a}}$ & 1.3 & $6.5^{\mathrm{a}}$ & 1.1 & $6.5^{\mathrm{a}}$ & 1.7 & $3.5^{\mathrm{b}}$ & 1.1 & $<0.0001$ \\
\hline Cluster $2(\mathrm{n}=62,54 \%)$ & $6.8^{\mathrm{ab}}$ & 1.4 & $6.7^{\mathrm{ab}}$ & 1.5 & $7.2^{\mathrm{a}}$ & 1.0 & $6.5^{\mathrm{b}}$ & 1.4 & 0.052 \\
\hline
\end{tabular}

${ }^{a-c}$ Values within a row with different superscripts are significantly different $(P<0.05)$.

${ }^{1}$ Consumers evaluated overall liking on a 9 -point hedonic category scale $(1=$ dislike extremely; $9=$ like extremely $)$.

${ }^{2}$ Clusters represent consumer subgroups that were homogeneous with regard to their overall liking of samples within the 3 product types as identified by agglomerative hierarchal cluster analysis.

${ }^{3}$ Modified = UHT SFA-reduced, MUFA-enriched milk; fat- and SFA-reduced, MUFA-enriched mild Cheddar cheese; and SFA-reduced butter. Control = UHT regular-SFA milk, regular-fat mild Cheddar cheese, and regular-fat butter. Comp1 = UHT whole milk; regular-fat Cheddar cheese; and regular-fat, SFA-reduced, MUFA-enriched butter. Comp2 = UHT semiskimmed milk, fat-reduced Cheddar cheese, and regular-fat spreadable butter.

${ }^{4}$ Data were analyzed for comparisons between products using 2-way ANOVA followed by Tukey's post hoc test. 
of texture liking $(P=0.016)$, although overall liking was not significantly different between the 2 samples.

Butter and Spread Samples. There was a significant difference in overall liking, liking of specific modalities, and purchase intent between the 4 butter and spread samples (all $P<0.0001$; Tables 5 and 6 ). The modified, control, and commercial regular-fat, SFA-reduced butter (Comp1) were liked significantly more than the commercial butter and sunflower oil spread (Comp2; all $P<0.0001$ ). The modified butter was not significantly different in overall liking, liking of any specific modality, or purchase intent from the control butter or the commercial butter manufactured from SFA-reduced, MUFA-enriched milk (Comp1).

\section{HCA of Consumer Liking Data}

Milk Samples. Cluster analysis revealed 3 patterns of liking for the UHT milks (Table 5). Cluster 1 (26\%; $\mathrm{n}=30$ ) liked the control milk significantly and substantially more than the other milks (modified: $P=$ 0.001; Comp1: $P<0.0001$; Comp2: $P=0.012$ ), with the commercial UHT whole milk (Comp1) receiving a very low mean score. The largest group, cluster $2(57 \%$; $\mathrm{n}=65$ ), gave high mean scores (between 6.6 and 7.4) across all 4 samples; their scores for the commercial UHT whole milk (Comp1) were significantly higher than for the control milk $(P=0.003)$, but their scores for the SFA-reduced, MUFA-enriched (modified) milk were not significantly different from any other samples. The smallest cluster, cluster $3(17 \% ; \mathrm{n}=20)$, were nondiscriminators who gave all the milks low scores. Cluster 1 predominantly comprised younger consumers $(\leq 44.0$ yr: $63 \%)$ who were more likely to be female (60\%), be from a higher SEC (1-4: 60\%), and have a lower BMI $\left(\leq 24.6 \mathrm{~kg} / \mathrm{m}^{2}: 57 \%\right)$ and a lower FNS score $(\leq 26.0: 63 \%)$. Cluster 2 was characterized by a relatively homogeneous group of consumers with regard to sex, BMI, and FNS score but contained a greater proportion of older individuals ( $>44.0 \mathrm{yr}: 60 \%$ ) and those from a lower SEC (5-8: 57\%). Cluster 3 contained a higher proportion of young consumers $(\leq 44.0 \mathrm{yr}$ : $70 \%)$ and those with a lower BMI value $\left(\leq 24.6 \mathrm{~kg} / \mathrm{m}^{2}\right.$ : $60 \%)$ and a higher FNS score (>26.0: $65 \%)$. The daily intake of milk was similar in each cluster, with most consumers claiming to drink up to $284 \mathrm{~mL} /$ d. Cluster 3 had a higher proportion (40\%) of consumers consuming more than $284 \mathrm{~mL} / \mathrm{d}$. In all clusters most individuals consumed semiskimmed milk. Cluster 3 was the most diverse because it had a higher proportion of consumers of either whole (15\%) or skim (20\%) milk compared with other clusters.

Cheese Samples. The HCA of the cheese overall liking data again revealed 3 clusters of consumers (Table 5). The largest cluster (cluster 1, 66\%; n = 76) gave high liking scores for all cheeses and rated the commercial cheese (Comp1) significantly higher than the modified cheese $(P=0.020)$ and the control

Table 6. Mean ratings ${ }^{1}$ of liking of appearance, flavor, and texture and purchase intent for milk, cheese, and butter samples ${ }^{2,3}$

\begin{tabular}{|c|c|c|c|c|c|}
\hline Product & Modified & Control & Comp1 & Comp2 & $P$-value \\
\hline \multicolumn{6}{|l|}{ Milk } \\
\hline Appearance & $6.7^{\mathrm{a}}$ & $6.6^{\mathrm{a}}$ & $6.8^{\mathrm{a}}$ & $6.6^{\mathrm{a}}$ & 0.512 \\
\hline Flavor & $6.1^{\mathrm{a}}$ & $6.2^{\mathrm{a}}$ & $6.1^{\mathrm{a}}$ & $6.3^{\mathrm{a}}$ & 0.653 \\
\hline Texture & $6.2^{\mathrm{a}}$ & $6.4^{\mathrm{a}}$ & $6.1^{\mathrm{a}}$ & $6.4^{\mathrm{a}}$ & 0.562 \\
\hline Purchase intent & $3.0^{\mathrm{a}}$ & $3.1^{\mathrm{a}}$ & $2.9^{\mathrm{a}}$ & $3.1^{\mathrm{a}}$ & 0.448 \\
\hline \multicolumn{6}{|l|}{ Cheese } \\
\hline Appearance & $6.5^{\mathrm{a}}$ & $6.8^{\mathrm{ab}}$ & $6.9^{\mathrm{b}}$ & $6.7^{\mathrm{ab}}$ & 0.022 \\
\hline Flavor & $6.0^{\mathrm{a}}$ & $6.6^{\mathrm{ab}}$ & $6.7^{\mathrm{b}}$ & $6.3^{\mathrm{ab}}$ & 0.013 \\
\hline Texture & $6.1^{\mathrm{a}}$ & $6.6^{\mathrm{b}}$ & $6.7^{\mathrm{b}}$ & $6.4^{\mathrm{ab}}$ & 0.001 \\
\hline Purchase intent & $2.9^{\mathrm{a}}$ & $3.1^{\mathrm{ab}}$ & $3.4^{\mathrm{b}}$ & $3.2^{\mathrm{ab}}$ & 0.015 \\
\hline \multicolumn{6}{|l|}{ Butter and spread } \\
\hline Appearance & $6.6^{\mathrm{b}}$ & $6.7^{\mathrm{b}}$ & $6.9^{\mathrm{b}}$ & $5.8^{\mathrm{a}}$ & $<0.0001$ \\
\hline Flavor & $6.4^{\mathrm{b}}$ & $6.3^{\mathrm{b}}$ & $6.7^{\mathrm{b}}$ & $4.9^{\mathrm{a}}$ & $<0.0001$ \\
\hline Texture & $6.5^{\mathrm{b}}$ & $6.4^{\mathrm{b}}$ & $6.8^{\mathrm{b}}$ & $5.0^{\mathrm{a}}$ & $<0.0001$ \\
\hline Purchase intent & $3.1^{\mathrm{bc}}$ & $2.9^{\mathrm{b}}$ & $3.3^{\mathrm{c}}$ & $2.2^{\mathrm{a}}$ & $<0.0001$ \\
\hline
\end{tabular}

${ }^{\mathrm{a}-\mathrm{c}}$ Values within a row with different superscripts are significantly different $(P<0.05)$.

${ }^{1}$ Consumers $(\mathrm{n}=115)$ evaluated appearance liking, flavor liking, and texture liking of each sample on a 9-point hedonic category scale $(1=$ dislike extremely; $9=$ like extremely). Ratings of purchase intent were evaluated on a 5 -point hedonic scale $(1=$ definitely would not buy; 5 = definitely would buy).

${ }^{2}$ Data were analyzed for comparisons between products using 2-way ANOVA followed by Tukey's post hoc test. ${ }^{3}$ Modified = UHT SFA-reduced, MUFA-enriched milk; fat- and SFA-reduced, MUFA-enriched mild Cheddar cheese; and SFA-reduced, MUFA-enriched butter. Control = UHT regular-SFA milk, regular-fat mild Cheddar cheese, and regular-fat butter. Comp1: UHT whole milk; regular-fat Cheddar cheese; and regular-fat, SFAreduced, MUFA-enriched butter. Comp2 = UHT semiskimmed milk, fat-reduced Cheddar cheese, and regularfat spreadable butter. 
cheese $(P=0.010)$ samples. Cluster $2(19 \% ; \mathrm{n}=22)$ disliked the SFA-reduced, MUFA-enriched (modified) and the commercial fat-reduced (Comp2) cheeses, rating the regular-fat control and commercial (Comp1) cheeses significantly higher. Cluster $3(15 \% ; \mathrm{n}=17)$ liked the fat-reduced commercial cheeses significantly and substantially more than all other cheeses. Cluster 1 was characterized by individuals who tended to have a lower FNS ( $\leq 26.0$ : $57 \%)$ and had a relatively equal split for age, sex, BMI, SEC demographics, and FNS scores. Cluster 2 was slightly higher in younger adults ( $\leq 44.0 \mathrm{yr}: 59 \%$ ), those from an upper SEC (1-4: 64\%), and those with higher FNS scores (>26.0: $59 \%)$; they were similarly split for sex and BMI. Cluster 3 was characterized by a higher proportion of females $(58 \%)$ as well as those with a lower BMI $\left(\leq 24.6 \mathrm{~kg} / \mathrm{m}^{2}: 65 \%\right)$ and older individuals ( $>44.0 \mathrm{yr}: 59 \%$ ). Most consumers claimed to eat cheese more than once per week; this was highest in cluster 3 , where only $6 \%$ of consumers ate cheese less than once per week.

Butter and Spread Samples. Three patterns that represented overall liking of the butter samples were revealed by HCA (Table 5). Cluster $1(34 \%$; $\mathrm{n}=39)$ and cluster $3(12 \% ; \mathrm{n}=14)$ both disliked the spread (Comp2; butter and sunflower oil blend) compared with all of the full-butter samples. However, in cluster 1 the consumers rated these 3 butter samples equally (all $P$ $<0.0001$ ). Cluster 3 liked the butter and sunflower oil product (Comp2) significantly less than the modified, control, and Comp1 butter samples $(P=0.002, P=$ 0.042 , and $P<0.0001$, respectively). Cluster $2(54 \%$; $\mathrm{n}=62)$ rated all samples with relatively high liking; the commercial butter (Comp1) was rated significantly higher than the commercial spread (Comp2; $P=$ $0.042)$. Cluster 1 contained a large proportion of females $(67 \%)$, individuals from a lower SEC (5-8: $59 \%)$, and individuals with a lower BMI value $\left(\leq 24.6 \mathrm{~kg} / \mathrm{m}^{2}\right.$ : $59 \%)$ and a lower FNS score ( $\leq 26.0: 59 \%)$ but was relatively equally split for age. Cluster 2 contained more males $(58 \%)$ and individuals with a higher BMI value $\left(>24.6 \mathrm{~kg} / \mathrm{m}^{2}: 52 \%\right)$ and a lower FNS $(\leq 26.0: 57 \%)$ but was relatively equally split with regard to age and SEC. Cluster 3 was equally split for age; it contained more females $(57 \%)$, individuals from a higher SEC (1-4: $57 \%)$, and individuals with a lower BMI $\left(\leq 24.6 \mathrm{~kg} / \mathrm{m}^{2}\right.$ : $78 \%)$ and higher FNS score (>26.0: 86\%). There were more low butter consumers in cluster 3 (93\% ate butter less than once per day) compared with other clusters.

\section{Acceptability of SFA-Reduced Cheese that Was Presented with Nutritional Information}

Presenting the SFA-reduced cheese with nutritional information about total fat and saturated fat content significantly increased overall liking (modified with information: $6.5 \pm 1.8$; modified: $6.2 \pm 1.9 ; P=0.04)$ and purchase intent (modified with information: $3.5 \pm 1.0$; modified: $2.9 \pm 1.2 ; P<0.001)$.

\section{DISCUSSION}

Supplementing the cow diet with plant oils or oilseeds is an effective and sustainable strategy for removing SFA from the food chain by partial milk fat replacement of SFA with unsaturated FA (Kliem and Shingfield, 2016). The primary objective of the current study was to determine consumer acceptability and purchase intent of modified dairy products when tasted in a blinded manner. A representative sample of UK consumers generally accepted the modified dairy product samples that were presented to them. A secondary aim of the study was to examine the effect of providing nutritional information about the modified cheese. We found that the overall liking and purchase intent of this SFA-reduced cheese increased when the cheese was presented along with nutrition information.

In line with other research that evaluated acceptability or sensory characteristics of FA-modified milk (Baer et al., 2001; Ramaswamy et al., 2001; Kitessa et al., 2004; Lynch et al., 2005), we found that our modified milk had no effect on the mean overall liking, liking of specific modalities, or purchase intent ratings across our consumer population $(\mathrm{n}=115)$. Our trained sensory panel observed some differences in sensory attributes between both modified and control samples and the commercial comparators. Therefore, it is likely that the disparities in milk flavor, mouthfeel, and aftereffect attributes were a result of disparate UHT manufacturing processes (Oupadissakoon et al., 2009) rather than milk composition.

In agreement with some of the literature (Palmquist et al., 1993; Chilliard and Ferlay, 2004; Givens and Shingfield, 2006), we observed that the modified cheese received lower mean ratings compared with the other 3 cheeses for overall liking, liking of specific modalities, and purchase intent. This cheese contained 7 and 9 $\mathrm{g} / 100 \mathrm{~g}$ less total fat and SFA, respectively, and $3 \mathrm{~g} / 100$ $\mathrm{g}$ less MUFA when compared with the most preferred sample, the regular-fat comparator. The reduction in liking is likely to have been driven by the differences in either appearance or texture outlined in the Results. Considering that the modified and control cheeses were produced using the same bacterial starter culture, the lower textural liking ratings for the modified cheese suggest that some attributes were affected by the total fat or FA composition of the sample. Fatty acid modification of cheese has previously been reported to lead to an alteration in the textural properties of 
cheeses (Palmquist et al., 1993; Chilliard and Ferlay, 2004; Givens and Shingfield, 2006). Comments collated from the consumers suggested that textural liking of the modified cheese was affected by its rubbery texture. The trained sensory panel in this study found the modified cheese to be more crumbly in appearance than the control, with a tendency (not significant) to be more rubbery. It is known that fat-reduced cheeses (25\% less fat than regular-fat counterparts) contain a more dense protein matrix in which agglomeration of fat globules is compromised, and this may lead to a rubbery texture and mouthfeel (Gunasekaran and Ak, 2002; Johnson et al., 2009). Indeed, our panel found the fat-reduced comparator (Comp2) to be significantly and substantially slower to disperse, have a much greater resistance to bite, be much more crumbly and mouth drying, and be slower to clear from the mouth than the standardfat comparator (Comp 1; Table 3). This could be explained by the fact that the fat-reduced commercial comparator (Comp 2) contained a further $6 \mathrm{~g} / 100 \mathrm{~g}$ less total fat than the modified cheese, which did not have these large or significant mouthfeel differences compared with the 2 regular-fat cheeses (control and Comp 1). However, further optimization is necessary because the consumer still liked the modified cheese less. It is probable that the use of optimized manufacturing procedures, which allow for the lower moisture content of fat-reduced cheese, could lead to cheeses with improved textural properties; such interventions include adding denatured whey protein to the cheese, adding a fat replacer, and homogenization of the cream (Johnson et al., 2009). Future work should consider the effect of such interventions on enhancing consumer acceptance of FA-modified (and fat-reduced) cheese.

The 3 butter samples were rated higher than the regular-fat spreadable butter (Comp2) for overall liking, liking of specific modalities, and purchase intent. It is possible that the liking ratings of the spreadable butter could have been confounded by the 0.2 to 0.5 $\mathrm{g} / 100 \mathrm{~g}$ lower salt content compared with the other butter samples. However, our sensory panel did not observe a significant difference in salt taste and aftertaste attributes between the butter and spread samples. The FA composition of the modified and commercial butters did not have a significant effect on the organoleptic properties of butter. An advantage of FA-modified butter is that it is more convenient to spread butter when it is cold (Palmquist et al., 1993; Chilliard and Ferlay, 2004; Givens and Shingfield, 2006). Butter firmness is largely determined by the ratio of $\mathrm{C} 16: 0$ to $\mathrm{C} 18: 1$ cis-9 in milk fat. An increase in milk fat C16:0 content and lowered short-chain FA concentrations are associated with a reduction in the spreadability of butter at colder temperatures (Chilliard and Ferlay, 2004). However, because we served all samples equilibrated to room temperature and on bread, we were unable to observe whether consumers had an increased preference for a specific butter based on firmness when used directly from the refrigerator.

The HCA indicated that for each dairy product type there were groups of consumers with distinctly different liking patterns. The largest milk cluster $(57 \%)$ liked the commercial whole milk significantly more than the control milk but gave high scores for all milk samples. Neither of the 2 smaller clusters rated the modified milk lower than the control. This suggests that milk could be a viable strategy for reducing SFA intake for the majority of consumers. The second largest cluster (26\%) liked the commercial whole milk (Comp 1) significantly less than the commercial semiskimmed milk (Comp 2); this cluster contained the highest proportion of regular consumers of semiskimmed milk compared with other clusters. The smallest cluster gave low liking scores to all milks, yet this cluster had the highest proportion of higher volume milk consumers. We speculate that this could be driven by the use of UHT milk for all samples in this study. Recent figures suggest that this type of milk contributes to only approximately $4 \%$ of liquid milk sales in Great Britain (AHDB, 2016).

For cheese, there was no difference in mean liking between the modified and control cheeses across all consumers, and this was mirrored in the largest (66\%) and smallest (15\%) consumer clusters. However, $19 \%$ of consumers liked the modified cheese significantly and substantially less than the control. This group had a slightly higher proportion of younger and higher SEC consumers, more people with a higher neophobia score, and more consumers who ate cheese less frequently. This may imply that these consumers were more sensitive to the changes in the FA profile or the slight reduction in fat content. It has previously been illustrated that oral sensitivity to FA could be related to the perception of fat in foods and that participants who were orally hypersensitive to $\mathrm{C} 18: 1$ could detect smaller differences in a custard varying in fat content compared with participants characterized as hyposensitive to this FA (Stewart et al., 2010). However, as the texture was liked less on average across the whole consumer group, this may imply that the changes in texture resulting from the fat profile or content had a greater influence on liking than any gustatory response to the more unsaturated FA. It would be interesting to see whether the processing conditions of the modified cheese could be optimized by a commercial manufacturer to improve the texture and increase liking of this cheese. The smallest cluster $(15 \%)$ had a preference for the fat-reduced cheese sample. This cluster, in which almost all participants consumed cheese more than once per week, consisted of 
a large proportion of older individuals and females with lower BMI. This fat-reduced cheese contained the lowest fat content and lowest MUFA content. The study by Stewart et al. (2010) suggests that oral sensitivity to FA also influenced BW, with participants who were orally hypersensitive to $\mathrm{C} 18: 1$ having lower BMI values. To some extent this supports our finding that those who preferred the fat-reduced, lower MUFA cheese had a lower BMI, and they might be more sensitive to MUFA levels. However, such inferences would need to be confirmed in an adequately powered trial. Interestingly, exposure to low-fat diets $(4-6 \mathrm{wk})$ has been shown to significantly increase fat taste sensitivity among lean and overweight or obese individuals and increase liking or preference for some low-fat foods (Stewart and Keast, 2012; Newman et al., 2016). Further research is warranted to investigate whether repeated exposure could increase consumer acceptance of FA-modified foods, such as dairy products.

For butter, there was no significant difference in liking between the modified sample and the control butter by the consumer group overall or by any consumer cluster. However, across all consumers and within each cluster the commercial spread was liked significantly less than the butter samples. This is a very interesting observation because it implies that consumers who will not currently switch from butter to spreads because they prefer the taste of butter are more likely to change to the SFA-reduced butter. Indeed, this modified butter would reduce the consumers' SFA intake to a similar extent as is achievable by switching to a spread. The largest butter cluster (54\%) gave substantially higher liking ratings to the spread sample than the other, implying that they were less influenced by the high PUFA content. This cluster contained more men, more consumers with a higher BMI, and more consumers with a high frequency of butter usage. Previous research has indicated that fat nondiscriminators may have greater abdominal adiposity compared with fat discriminators (Liang et al., 2012). The smallest cluster $(12 \%)$ rated all butter and spread samples lower than the other clusters; this cluster had very few frequent butter consumers.

Despite previous observations that have suggested that consumers may relate total fat reduction to reduced pleasantness and an altered sensorial profile (Tuorila et al., 1994), we found that informed consumers gave higher overall liking and purchase intent ratings for the modified cheese compared with tasting this cheese sample in a blinded manner. This is in line with previous work that has demonstrated a positive influence of nutritional information on acceptance of unfamiliar foods (Kähkönen et al., 1996; Tuorila et al.,
1998). Furthermore, the overall liking of the modified cheese with information was similar to the mean ratings given by consumers when they tasted the control and fat-reduced cheeses in a blinded manner. Some research has demonstrated that health-related nutritional labels on cheese (i.e., fat and salt content) could affect the sensory expectation and perception of related sensory attributes but may not detrimentally affect overall liking of cheese; this suggests that health-related labels may be used as a priming method to influence more healthful food choices (Schouteten et al., 2015). Raising consumer awareness of the taste of healthful foods may also be beneficial. It has been demonstrated that the provision of taste information encouraged the selection of previously unfamiliar foods, including low-fat varieties of cheese and margarine (Schickenberg et al., 2011).

The present study has several possible limitations. It could be argued that the number of attributes assessed in our QDA sensory evaluation (36, 42, and 53 attributes for butter or spread, milk, and cheese, respectively) could have led to a halo effect as a result of panelists forming logistical associations between attributes in specific modalities. However, using a fully trained sensory panel minimized this effect. Furthermore, having a greater number of attributes enabled the ability to differentiate between samples, and sets of up to 100 attributes have been evaluated in previous sensory studies (Vandeginste et al., 1998; Stone et al., 2012). As a result of time constraints, it was not feasible to assess the effect of information provision on acceptability of the milk and butter samples. In addition, not all of the product types were processed under standardized conditions (i.e., different process parameters and milk sources were used), and it is acknowledged that this could have affected product acceptance (Markey et al., 2015) independent of variations in FA or total fat content. Furthermore, it was not feasible to purchase all commercial samples in a single batch (cheese and butter or spread) or in units that were consistent with those of the modified and control dairy products. The modified cheese had a $5 \mathrm{~g} / 100 \mathrm{~g}$ lower total fat content than the control sample due to the lower fat content of the experimental milk (Markey et al., 2017); this makes it difficult to differentiate between the effect of SFA and total fat reduction on consumer acceptance of the product. Butter was evaluated on bread by both the sensory panel and the consumers. Therefore, future studies could evaluate additional features such as spreadability. Furthermore, the cluster groups were not all adequately powered, and therefore the results should be interpreted with caution.

Identifying dietary changes that have the potential to enhance diet quality has important implications for 
designing attainable dietary recommendations for public health (Verger et al., 2014). A simulation analysis indicated that encouraging young adults to replace 3 high-SFA products in their diet, including Dutch hard cheese, meats, and milk, with low-SFA alternatives had the potential to increase compliance with dietary recommendations ( $\leq 10 \%$ of total energy) from 23 to $86 \%$ (Schickenberg et al., 2009). The current work confirms that novel dairy products that had a portion of SFA content replaced with cis-MUFA through a bovine feeding regimen were acceptable to consumers. Future work is required to examine whether real-life dietary replacement strategies have the potential to reduce SFA intake at a population level while minimizing changes to dietary patterns of consumers.

\section{CONCLUSIONS}

The findings from the present study indicate that the consumer acceptance of SFA-reduced, MUFA-enriched milk and butter was similar to that of commercially available comparators. The SFA-reduced, MUFAenriched cheese was less liked than the commercial regular-fat cheese comparator and the texture was less liked compared with both of the regular-fat cheeses tested. However, tasting the modified cheese with nutritional information increased the overall liking and purchase intent compared with tasting the same sample in a blinded manner. Future work should consider how optimization of the textural properties of the FA-modified (and fat-reduced) cheese as well as the provision of nutrition information affect consumer acceptability of this dairy product.

\section{ACKNOWLEDGMENTS}

The study was funded by the Medical Research Council (MR/K020218/1) in collaboration with Arla Foods UK. The authors gratefully acknowledge AAK Ltd. (UK) for kindly donating the high-oleic sunflower oil. None had any involvement in the study design, analysis, or interpretation of results. The authors gratefully acknowledge the consumers from the Reading area and members of sensory panel at the Department of Food and Nutritional Sciences, University of Reading, for their time and enthusiasm. We thank Val Bines (University of Reading) for her input into the cheese manufacturing, Chris Drake (University of Reading) for preparing the dairy samples for sodium content analysis, and Luke Hewitt (University of Reading) for his assistance with recruitment and data collection, and we acknowledge Amanda Hargreaves's (University of Reading) contribution to pilot data collection.

\section{REFERENCES}

AHDB (Agriculture and Horticulture Development Board Dairy). 2016. GB liquid milk expenditure and volume sales. Accessed Sep. 5, 2016. http://dairy.ahdb.org.uk/market-information/dairy-sales -consumption/liquid-milk-market/.

Baer, R. J., J. Ryali, D. J. Schingoethe, K. M. Kasperson, D. C. Donovan, A. R. Hippen, and S. T. Franklin. 2001. Composition and properties of milk and butter from cows fed fish oil. J. Dairy Sci. 84:345-353.

Beck, T. K., S. Jensen, S. H. Simmelsgaard, C. Kjeldsen, and U. Kidmose. 2015. Consumer clusters in Denmark based on coarse vegetable intake frequency, explained by hedonics, socio-demographic, health and food lifestyle factors. A cross-sectional national survey. Appetite 91:366-374.

Beckley, J. H., D. Paredes, and K. Lopetcharat. 2012. Product Innovation Toolbox: A Field Guide to Consumer Understanding and Research. Wiley, New York, NY.

Chilliard, Y., and A. Ferlay. 2004. Dietary lipids and forages interactions on cow and goat milk fatty acid composition and sensory properties. Reprod. Nutr. Dev. 44:467-492.

COMA (Committee on Medical Aspects of Food Policy). 1994. Nutritional Aspects of Cardiovascular Disease, Department of Health (Report on Health and Social Subjects, No. 46). HMSO, London, United Kingdom.

Drake, M. A., S. C. McIngvale, P. D. Gerard, K. R. Cadwallader, and G. V. Civille. 2001. Development of a descriptive language for Cheddar cheese. J. Food Sci. 66:1422-1427.

Givens, D. I. 2008. Session 4: Challenges facing the food industry in innovating for health. Impact on CVD risk of modifying milk fat to decrease intake of SFA and increase intake of cis-MUFA. Proc. Nutr. Soc. 67:419-427.

Givens, D. I., and K. J. Shingfield. 2006. Optimising dairy milk fatty acid composition. Pages 252-280 in Improving the Fat Content of Foods. C. Williams and J. Buttriss, ed. Woodhead, Cambridge, United Kingdom.

Gunasekaran, S., and M. M. Ak. 2002. Cheese Rheology and Texture. CRC Press, Boca Raton, FL.

Johnson, M. E., R. Kapoor, D. J. McMahon, D. R. McCoy, and R. G. Narasimmon. 2009. Reduction of sodium and fat levels in natural and processed cheeses: Scientific and technological aspects. Comp. Rev. Food Sci. 8:252-268.

Jones, E. L., K. J. Shingfield, C. Kohen, A. K. Jones, B. Lupoli, A. S. Grandison, D. E. Beever, C. M. Williams, P. C. Calder, and P. Yaqoob. 2005. Chemical, physical, and sensory properties of dairy products enriched with conjugated linoleic acid. J. Dairy Sci. 88:2923-2937.

Kähkönen, P., H. Tuorila, and H. Rita. 1996. How information enhances acceptability of a low-fat spread. Food Qual. Prefer. 7:87-94.

Kitessa, S. M., S. K. Gulati, G. C. Simos, J. R. Ashes, T. W. Scott, E. Fleck, and P. C. Wynn. 2004. Supplementation of grazing dairy cows with rumen-protected tuna oil enriches milk fat with n-3 fatty acids without affecting milk production or sensory characteristics. Br. J. Nutr. 91:271-278.

Kliem, K. E., and K. J. Shingfield. 2016. Manipulation of milk fatty acid composition in lactating cows: Opportunities and challenges. Eur. J. Lipid Sci. Technol. 118:1661-1683.

Kliem, K. E., K. J. Shingfield, K. M. Livingstone, and D. I. Givens. 2013. Seasonal variation in the fatty acid composition of milk available at retail in the United Kingdom and implications for dietary intake. Food Chem. 141:274-281.

Krause, A. J., K. Lopetcharat, and M. A. Drake. 2007. Identification of the characteristics that drive consumer liking of butter. J. Dairy Sci. 90:2091-2102.

Liang, L. C. H., J. Sakimura, D. May, C. Breen, E. Driggin, B. J. Tepper, W. K. Chung, and K. L. Keller. 2012. Fat discrimination: A phenotype with potential implications for studying fat intake behaviors and obesity. Physiol. Behav. 105:470-475.

Livingstone, K. M., J. A. Lovegrove, and D. I. Givens. 2012. The impact of substituting SFA in dairy products with MUFA or PUFA 
on CVD risk: Evidence from human intervention studies. Nutr. Res. Rev. 25:193-206.

Lock, A. L., D. I. Givens, and D. E. Bauman. 2014. Dairy fat: Perceptions and realities. Pages $174-197$ in Milk and Dairy Products as Functional Foods. A. Kanekanian, ed. Wiley, New York, NY.

Lourenço, M., E. Ramos-Morales, and R. J. Wallace. 2010. The role of microbes in rumen lipolysis and biohydrogenation and their manipulation. Animal 4:1008-1023.

Lynch, J. M., A. L. Lock, D. A. Dwyer, R. Noorbakhsh, D. M. Barbano, and D. E. Bauman. 2005. Flavor and stability of pasteurized milk with elevated levels of conjugated linoleic acid and vaccenic acid. J. Dairy Sci. 88:489-498.

Markey, O., J. A. Lovegrove, and L. Methven. 2015. Sensory profiles and consumer acceptability of a range of sugar-reduced products on the UK market. Food Res. Int. 72:133-139.

Markey, O., D. Vasilopoulou, D. I. Givens, and J. A. Lovegrove. 2014. Dairy and cardiovascular health: Friend or foe? Nutr. Bull. 39:161171.

Markey, O., D. Vasilopoulou, K. E. Kliem, A. Koulman, C. C. Fagan, K. Summerhill, L. Y. Wang, A. S. Grandison, D. J. Humphries, S. Todd, K. G. Jackson, D. I. Givens, and J. A. Lovegrove. 2017. Plasma phospholipid fatty acid profile confirms compliance to a novel saturated fat-reduced, monounsaturated fat-enriched dairy product intervention in adults at moderate cardiovascular risk: A randomized controlled trial. Nutr. J. 16:33.

Merrill, A. L., and B. K. Watt. 1973. Energy value of foods: Basis and derivation. Agriculture Handbook 74. USDA, Agricultural Research Service, Washington, DC.

Moskowitz, H. R., S. Porretta, and M. Silcher. 2008. Concept Research in Food Product Design and Development. Wiley, New York, NY.

Newman, L. P., D. P. Bolhuis, S. J. Torres, and R. S. J. Keast. 2016. Dietary fat restriction increases fat taste sensitivity in people with obesity. Obesity (Silver Spring) 24:328-334.

Oupadissakoon, G., D. H. Chambers, and E. Chambers IV.. 2009. Comparison of the sensory properties of ultra-high temperature (UHT) milk from different countries. J. Sens. Stud. 24:427-440.

Palmquist, D. L., A. Denise Beaulieu, and D. M. Barbano. 1993. Feed and animal factors influencing milk fat composition. J. Dairy Sci. 76:1753-1771

Peryam, D. R., and F. J. Pilgrim. 1957. Hedonic scale method of measuring food preferences. Food Technol. 11(Suppl.):9-14.

Pliner, P., and K. Hobden. 1992. Development of a scale to measure the trait of food neophobia in humans. Appetite 19:105-120.

Ramaswamy, N., R. J. Baer, D. J. Schingoethe, A. R. Hippen, K. M. Kasperson, and L. A. Whitlock. 2001. Short communication: Consumer evaluation of milk high in conjugated linoleic acid. J. Dairy Sci. 84:1607-1609.

Rapp, E., A. Ostrom, W. Osika, A. Englund, J. Annett, and I. B. Gustafsson. 2009. Preference for full-fat over low-fat foods among individuals suffering from coronary heart disease and healthy controls. Physiol. Behav. 98:489-497.

Richardson-Harman, N. J., R. Stevens, S. Walker, J. Gamble, M. Miller, M. Wong, and A. McPherson. 2000. Mapping consumer perceptions of creaminess and liking for liquid dairy products. Food Qual. Prefer. 11:239-246.
Rios, R. V., M. D. F. Pessanha, P. F. de Almeida, C. L. Viana, and S. C. S. Lannes. 2014. Application of fats in some food products. Food Sci. Technol. (Campinas) 34:3-15.

Rose, D., and D. Pevalin. 2010. SOC2010 volume 3: The National Statistics Socio-economic classification (NS-SEC rebased on SOC2010). User manual. Palgrave Macmillan, Basingstoke, United Kingdom.

Schickenberg, B., P. van Assema, J. Brug, and N. K. de Vries. 2011. Information about the taste stimulates choice of unfamiliar healthful food products. J. Hum. Nutr. Diet. 24:603-611.

Schickenberg, B., P. van Assema, J. Brug, J. Verkaik-Kloosterman, M. C. Ocké, and N. K. de Vries. 2009. Replacing foods high in saturated fat by low-saturated fat alternatives: A computer simulation of the potential effects on reduction of saturated fat consumption. Br. J. Nutr. 102:478-483.

Schouteten, J. J., H. De Steur, S. De Pelsmaeker, S. Lagast, I. De Bourdeaudhuij, and X. Gellynck. 2015. Impact of health labels on flavor perception and emotional profiling: A consumer study on cheese. Nutrients 7:10251-10268.

Sriperm, N. G. M. Pesti, and P. B. Tillman. 2011. Evaluation of the fixed nitrogen-to-protein ( $\mathrm{N}: \mathrm{P})$ conversion factor (6.25) versus ingredient specific N:P conversion factors in feedstuffs. J. Sci. Food Agric. 91:1182-1186.

Stewart, J. E., C. Feinle-Bisset, M. Golding, C. Delahunty, P. M. Clifton, and R. S. Keast. 2010. Oral sensitivity to fatty acids, food consumption and BMI in human subjects. Br. J. Nutr. 104:145152.

Stewart, J. E., and R. S. J. Keast. 2012. Recent fat intake modulates fat taste sensitivity in lean and overweight subjects. Int. J. Obes. (Lond.) 36:834-842.

Stone, H., R. Bleibaum, and H. A. Thomas. 2012. Sensory Evaluation Practices. Academic Press, Cambridge, MA.

Tuorila, H., A. Andersson, A. Martikainen, and H. Salovaara. 1998. Effect of product formula, information and consumer characteristics on the acceptance of a new snack food. Food Qual. Prefer. 9:313-320.

Tuorila, H., A. V. Cardello, and L. L. Lesher. 1994. Antecedents and consequences of expectations related to fat-free and regular-fat foods. Appetite 23:247-263.

Vandeginste, B. G. M., D. L. Massart, L. M. C. Buydens, S. De Jong, P. J. Lewi, and J. Smeyers-Verbeke. 1998. Introduction to Part B. Pages $1-5$ in Data Handling in Science and Technology. Vol. 20, Pt. 2. B. G. M. Vandeginste, D. L. Massart, L. M. C. Buydens, S. De Jong, P. J. Lewi, and J. Smeyers-Verbeke, ed. Elsevier, Amsterdam, the Netherlands.

Vargas-Bello-Pérez, E., K. Fehrmann-Cartes, G. Íñiguez-González, P. Toro-Mujica, and P. C. Garnsworthy. 2015. Short communication: Chemical composition, fatty acid composition, and sensory characteristics of Chanco cheese from dairy cows supplemented with soybean and hydrogenated vegetable oils. J. Dairy Sci. 98:111-117.

Verger, E. O., B. A. Holmes, J. F. Huneau, and F. Mariotti. 2014. Simple changes within dietary subgroups can rapidly improve the nutrient adequacy of the diet of French adults. J. Nutr. 144:929-936.

Westcombe, A., and J. Wardle. 1997. Influence of relative fat content information on responses to three foods. Appetite 28:49-62. 